\title{
Introduction: Challenges and Opportunities in the Studies of Translocal Chinese
}

\author{
Chia-Yuan Huang \\ Research Center for Humanities and Social Sciences, Academia Sinica, \\ Taipei City, Taiwan \\ chiayuan@gate.sinica.edu.tw
}

The role of overseas Chinese and their economic contribution to China's modernization process has been fertile ground for research. This issue contains three research articles and two research notes, all of which deal with overseas Chinese and their relation to translocal social development while putting forward some interesting and thought-provoking research findings. Over the past two centuries, Chinese people have scattered all over the world, including North America, Singapore, Malaysia, and Myanmar-so these five articles cover each of the countries and regions, researching topics ranging from remittance networks, cultural heritage, and visual art to political participation. Together, they demonstrate the broad scope of overseas Chinese geographical distribution and influence in the world.

Since the mid-nineteenth century, many Chinese have gone overseas-mainly North America and Southeast Asia—to seek work opportunities as laborers. After accumulating enough wealth, they would contribute to their hometowns' development by remitting money back to China. Some of them even participated in the political and public affairs of their hometowns, becoming eventually the cornerstone of the emerging social classes in China of the mid-nineteenth to mid-twentieth centuries. Bowei Chiang's and Ania Gricuk's articles discuss the impact of overseas Chinese's remittance networks on the development of their home country.

Bo-wei Chiang's article focuses on Chinese laborers who migrated from Kaiping, Guangdong to the United States and Canada in the mid-nineteenth century to engage in manual work such as railway construction or agricultural land development. Many of these early migrants laid the foundation for modernized infrastructure in their hometowns with their hard-earned money, which helped build houses and public utilities such as roads, hospitals, and 
schools. By the end of the nineteenth century, Kaiping's rapid modernization and acceptance of Western ethos had altered the local social culture and landscape considerably, especially through the distinctive design and architecture of diaolou (雕樓) towers, which have now enabled the city to develop a reputation as a tourist attraction boasting a world cultural heritage. The local government took advantage of these assets and transformed its cultural heritage into resources for cultural tourism and economic development. Chiang's research on the Kaiping diaolou not only illustrates the transnational flow of people, capital, and culture in the nineteenth century, but also allows readers to understand the migration history and spatial practices of overseas Chinese more deeply.

Ania Gricuk's article looks at the remittances sent by overseas Chinese workers to their hometowns from the 185 os to the 1930s. The article draws attention to two types of private remittance networks - through shuike (水客 “water guests" or couriers) and jinshanzhuang (金山庄 "gold mountain shops")— which served as points of connection between migrant workers and their relatives in their hometowns. These private networks made possible a mass flow of information, money, and commodities, forming a community that was not bound by physical space. Unlike postal services and other established national networks, these two remittance networks were initiated and developed by overseas Chinese themselves. This operation mode, according to Gricuk, cannot be pigeonholed as a form of Chinese capitalism as elucidated by Gregor Benton and Hong Liu, nor does it fit into what Lane J. Harris calls transnational capitalism, but rather something that goes beyond the nation-state and the Chinese identity. This remittance trade was based on mutual trust between people who shared the same dialect or village, giving rise to a unique exchange system that transcended national boundaries and sovereignty.

Chiang's and Gricuk's articles offer a useful glimpse of how overseas Chinese working in North America stayed connected with their hometowns in China, as North America - along with Southeast Asia - are the areas where most overseas Chinese are concentrated. Jason Lim's article, on the other hand, explores the ideology of ethnic Chinese and their influence on Singapore from 1959 to 1979. Notwithstanding its self-image as a free and progressive multicultural society, Singapore was for a time considered potentially susceptible to Chinese chauvinism and communist influence as ethnic Chinese compose up to $75 \%$ of its population. Through the Singapore government's vigilance and efforts to combat Chinese chauvinism, Lim believes, the sense of belonging and loyalty to the Singaporean nation among local Chinese has been inadvertently consolidated. 
In addition to the three research articles mentioned above, this issue also contains two research notes that present important observations of ethnic Chinese in Southeast Asia.

Ling-Ting Chiu's article introduces the ink paintings of two ethnic Chinese painters, Chen Wen-hsi and Chung Chen-sun, based in Singapore and Malaysia respectively. In the twentieth century, these two painters had used traditional Chinese ink painting techniques to create new forms of artistic expression, incorporating into their paintings the tumultuous history of Western colonialism in Southeast Asia and Singapore's multi-ethnic character. As a result, a distinct Nanyang style that combines Western modern art, Chinese ink painting, and Southeast Asian elements was created, which also opened a new chapter for the tradition of literati painting.

Last but not least, Yu Szu-Tu's timely article on the public participation of Burmese Chinese sheds new light on the military coup that took place in Myanmar this February, which resulted in the detention of many prominent political figures and a subsequent state of emergency. Considering these precarious political circumstances, the TCEA editorial board decided to publish this article with its valuable insights into Burmese political culture from the perspective of the Sino-Burmese as an ethnic minority group. Through in-depth interviews, Szu-Tu has found significant differences in the responsiveness of ethnic Chinese in different regions to broader Burmese society. Because of past anti-Chinese riots and military coups, ethnic Chinese in Myanmar generally held the belief that they have little influence on Burmese politics, so they tended to keep a passive distance from local politics. However, things have taken a turn as the new generation of ethnic Chinese have begun to actively participate in anti-military social movements, and whether the recent coup will spur more young Burmese Chinese to show interest in local political affairs is a topic that deserves attention.

Overseas Chinese are the world's largest group of overseas immigrants. The three research articles and two research notes in this issue examine the interaction and mutual influences of ethnic Chinese and the societal, political, and cultural respects of their host countries. The main purpose of the early Chinese emigrants was simply to earn a living, but they ended up making invaluable contributions to modern civilization and the economic development of America and Southeast Asia in different historical stages, while facilitating infrastructure building in their hometowns. As overseas Chinese are playing an increasingly important role globally, the TCEA expects to see more original topics and related research on Chinese migration in the future that explore the opportunities, challenges, and prospects of the field. 